\title{
Serum Bilirubin as a Predictor of Coronary Artery Disease Severity in Patients Undergoing Primary Percutaneous Coronary Intervention
}

\author{
Tarek Salah Khalil1', Waleed Abdou Ibrahim¹, Mohamed Asem Ali Elmalla² \\ ${ }^{1}$ Department of Cardiology, Faculty of Medicine, Menoufia University Hospitals, Menoufia, Egypt \\ ${ }^{2}$ El-Mahalla Cardiology, Mahalla Cardiac Centre, Mahalla, Egypt \\ Email: elmalla1682015@gmail.com
}

How to cite this paper: Khalil, T.S., Ibrahim, W.A. and Elmalla, M.A.A. (2019) Serum Bilirubin as a Predictor of Coronary Artery Disease Severity in Patients Undergoing Primary Percutaneous Coronary Intervention. World Journal of Cardiovascular Diseases, 9, 309-323.

https://doi.org/10.4236/wjcd.2019.95027

Received: April 5, 2019

Accepted: May 5, 2019

Published: May 8, 2019

Copyright $\odot 2019$ by author(s) and Scientific Research Publishing Inc. This work is licensed under the Creative Commons Attribution International License (CC BY 4.0). http://creativecommons.org/licenses/by/4.0/

\section{Open Access}

\begin{abstract}
Introduction: Coronary artery disease (CAD) is one of the most common causes of death worldwide. In 2010, about 7 out of total 53 million deaths were due to ischemic heart disease. The aim of this study is to evaluate the relationship of serum bilirubin level with the severity and complexity of coronary artery disease $(\mathrm{CAD})$ in the patients undergoing primary percutaneous coronary intervention (PCI). Materials and Methods: 70 patients with STEMI who were undergoing primary PCI were included in the study. All the patients included in the study were subjected to full routine investigations and standard coronary angiographic projections. Total bilirubin level was measured and the patients were divided into two groups. Group 1 was with serum TB $(<1 \mathrm{mg} / \mathrm{dl})$ and Group 2 was with serum TB $(>1 \mathrm{mg} / \mathrm{dl})$. Severity and complexity of coronary artery lesions will be assessed using Gensini score. Results: After PCI, the two studied groups were compared regarding the number of vessels affected by one and more than one vessel disease. Single vessel disease was frequent in Group 2 (71\%) with significant p value (0.003). Cardiac enzymes (troponin I) was more in Group 1 (S. Bil $<1$ ) with significant $\mathrm{p}$ value (0.02). Also (ALT, AST) were more in Group 1 ( $\mathrm{p}$ value $=$ 0.01 ). By comparing the 2 groups, there was a significant difference regarding (EF) between both which was less in Group 1 (S.TB $<1$ ) than Group 2 (S.TB $>1)$, p value significance $(0,0001)$. Also GENSENI was more in Group $1(\mathrm{~S} . \mathrm{TB}<1)$ than Group $2(\mathrm{~S} . \mathrm{TB}>1)$ with mean $(80.35$ vs 34.71$)$ and significant $\mathrm{p}$ value $(0.0001)$. There was a highly significant negative correlation between serum bilirubin \& GENSENI score $(r=-0.762$, $\mathrm{p}$ value 0.0001$)$. Regarding the incidence of complications, incidence was more in Group 1 (S.TB $<1)$ than in Group $2(\mathrm{~S} . \mathrm{TB}>1)$, which means a significant difference be-
\end{abstract}


tween both groups with significant $\mathrm{p}$ value $(0.0001)$. There was a significant negative correlation between serum bilirubin \& incidence of complications ( $R$ $=-0.38$, $\mathrm{p}$ value 0.001$)$. Also, there was a significant negative correlation between GENSINI score, complication and bilirubin among both groups ( $\mathrm{r}$ : $-0.762 \backslash-0.38)$ with $\mathrm{p}$ value $(0.0001 \backslash 0.001)$ respectively. Conclusion: In conclusion, our results suggested that the Serum Bilirubin level is inversely correlated with the severity of $\mathrm{CAD}$. Also, the SB level is an independent predictor of cardiovascular events in CAD patients. Understandably, our findings need further verification by large-scale, multicenter clinical trials in the future.

\section{Keywords}

Serum Bilirubin, Coronary Artery Disease, Prognosis, Risk Factors

\section{Introduction}

Coronary artery disease (CAD) is one of the most common causes of death worldwide. In 2010, about 7 out of total 53 million deaths were due to ischemic heart disease [1].

Atherosclerosis is the disease primarily responsible for most acute coronary syndrome (ACS) cases. Approximately $90 \%$ of myocardial infarctions (MIs) result from an acute thrombus that obstructs an atherosclerotic coronary artery. Plaque rupture and erosion are considered to be the major triggers of coronary thrombosis [2].

MI is diagnosed when either of the following two criteria is met [3].

1) Symptoms of ischemia.

2) New or presumed new significant ST-Segment-T wave (ST-T) changes or new left bundle branch block (LBBB).

3) Development of pathologic Q waves on the ECG.

4) Imaging evidence of new loss of viable myocardium or a new regional wall motion abnormality.

5) Identification of an intracoronary thrombus by angiography or autopsy.

Primary PCI, defined as percutaneous catheter intervention in the setting of STEMI without previous fibrinolysis, is the preferred reperfusion strategy. It has replaced fibrinolysis in patients with STEMI, provided it can be performed in a timely manner in high-volume PCI centers with experienced operators and 24 $\mathrm{h} / 7$ days week catheterization laboratory activation [4].

Bilirubin, a product of heme metabolism, was later observed to possess: Vasodilatory, anti-oxidant, anti-inflammatory, anti-mutagenic, immune modulatory, anti-proliferative and anti-apoptotic on vascular cells [5]. It has also been suggested to have a lipid-lowering effect by reducing plasma and low-density lipid peroxidation [6]. By virtue of these properties, bilirubin was hypothesized to have a protective effect in coronary artery disease (CAD) [7]. 
Studies have shown that different forms of circulating bilirubin and its precursor, biliverdin, have the ability to remove the reactive forms of oxygen. They also prevent the oxidation of low-density-lipoprotein particles and monocyte chemotaxis all which are considered as stages of atherosclerosis [8].

Although various main risk factors have been identified for atherosclerosis, including hypertension (HTN), hyperlipidemia, diabetes mellitus (DM), smoking, etc., it seems that there are other factors increasing the chance of CAD [9]. However, there are other factors, like plasma bilirubin level, with protective and preventive properties against coronary atherosclerosis [10].

Higher serum bilirubin levels were associated with good collateral development as compared to poor collateral development $(0.80 \pm 0.27 \mathrm{mg} / \mathrm{dL}$ vs $0.53 \pm$ $0.19 \mathrm{mg} / \mathrm{dL}, \mathrm{p}<0.001)$. These findings suggest a possible protective effect of elevated serum bilirubin levels against myocardial ischemia in patients with chronic total coronary occlusion with collaterals limiting infarct size and providing additional blood flow to the ischemic area [11].

According to Wei et al. (2012), a significant inverse correlation between CAD and total bilirubin $(\mathrm{n}=1260)$ in patients who underwent coronary angiography [12].

\section{The Aim of Work}

The aim of this study is to evaluate the relationship of serum bilirubin level with the severity and complexity of coronary artery disease (CAD) in the patients undergoing primary percutaneous coronary intervention (PCI).

\section{Materials and Methods}

- 70 patients with STEMI (more than 2 contiguous leads with ST segment elevation of $2.5 \mathrm{~mm}$ or more in male $<40$ years, $2 \mathrm{~mm}$ or more in male $>40$ years, or $1.5 \mathrm{~mm}$ in female in leads $\mathrm{v} 2-\mathrm{v} 3$ and/or $1 \mathrm{~mm}$ or more in other leads) who will undergo primary PCI were included in the study after taking informed consent.

- Exclusion Criteria:

$>$ Malignancy.

$>$ Those who had an alcohol abuse history.

$>$ Severe heart failure $(\mathrm{EF} \leq 30 \%)$.

Acute coronary syndrome in the past three months.

$>$ Kidney problem (creatinine $>2 \mathrm{mg} / \mathrm{dl}$ ).

Erythrocyte diseases.

$>$ Connective tissue diseases.

$>$ Chronic liver diseases.

- All the patients included in the study will be subjected to full history, full examination, twelve leads ECG and routine laboratory tests including CBC, KFTS, LFTS, lipid profile.

- The clinical features, coronary angiographic findings and treatments will be 
collected when the patients were admitted into the hospital.

- Total bilirubin level was measured by the standard method of photometry in the serum of all patients and then the patients were divided into two groups, according to their bilirubin levels: patients with high total bilirubin $(>1$ $\mathrm{mg} / \mathrm{dl})$ and the patients with a low level total level ( $\leq 1 \mathrm{mg} / \mathrm{dl})[13]$.

- All these patients will receive a loading dose of $325 \mathrm{mg}$ aspirin and $600 \mathrm{mg}$ clopedrogril. Maintenance dose: $150 \mathrm{mg}$ clopedrogril for one week, then 75 mg clopedrogil, according to their stent type [14].

- All of them subjected to left heart catheterization LCA \& RCA will be visualized in different projection. Once lesion identified, revascularization attempted.

- Successful PCI was defined as achieving TIMI 3 flow after primary angioplasty [15].

- Severity and complexity of coronary artery lesions will be assessed using Gensini score.

- The Gensini score will be calculated for each patient from the coronary arteriogram by assigning a severity score to each coronary stenosis according to the degree of luminal narrowing and its geographic importance [16].

- According to Gensini severity score, a severity coefficient will be given for each segment $(0,1,2,4,8,16$, or 32 according to the degree of stenosis) and the importance of the segment was rated ( 5 for the left main trunk to 0.5 for the most distal segments). Consequently, total digital Gensini scores were obtained that indicated the severity of CAD [17].

\section{Degree of Stenosis (\%) Score}

251

$26-502$

$51-754$

$76-908$

$91-9916$

10032

Left Coronary Artery Multiplication Factor

Left main coronary artery (LMCA) 5

Left anterior descending artery (LAD):

Proximal segment 2.5

Middle segment 1.5

Apical segment 1

1) Diagonal 1

2) Diagonal 0.5

Circumflex Artery (Cx)

Proximal segment 2.5 (3.5) a

Middle segment 1 (2) a

Distal segment 1 (2) a

Obtus marginal 1 
Posterolateral branch 0.5

\section{Right Coronary Artery (RCA)}

Proximal segment 1

Middle segment 1

Distal segment 1

Posterior descending artery (PDA) 1

a: If coronary artery dominant, multiplication factor has been used number in the parenthesis.

For example:

- $\quad$ Left anterior descending artery: Proximal (2.5), 98\% (16), score: $2.5 \times 16$ = 40; Middle (1.5), $70 \%$ (4), Score: $1.5 \times 4=6$.

- Circumflex artery: Obtuse marginal branch (1), $80 \%$ (8), proximal Score: $8 \times 1=8$.

- $\quad$ Right coronary artery: Proximal (1), 99\% (16), Score: $1 \times 16=16$.

Final Gensini score: $40+6+8+16=70$.

- In-hospital complications including (death, stent thrombosis, recurrent MI, ventricular arrhythmias, HF \& mechanical complications) will be assessed in all patients undergoing primary PCI.

\section{Result}

The studied population was divided into two groups according to their total bilirubin level: Group (I) in which TB $<1.0$ (No. 49) and Group (II) in which TB $\geq$ 1.0 (No. 21) (Table 1).

The two groups were studied according to risk factors (HTN /DM /Smoking). The most commonly observed risk factor was DM (45 patients 69\%). The least factor was smoking (37 patients 52\%). By comparison, there was no significant relationship between both groups regarding risk factors (Table 2).

Patients were classified according to their presentation. The most commonly observed presentation was anterior STEMI (39\%), then inferior STEMI (34\%). The least was isolated posterior STEMI (4\%) (Table 3).

After PCI the two studied groups were compared regarding the number of vessels affected to one \& more than one vs disease. Single vessel disease (culprit VS) was frequent in Group 2 (71\%) more than Group 1 (48\%). More than one vessel were less in Group 2 (29\%) than Group 1 (52\%) with significant p value (0.003) (Table 4).

The two studied groups were compared according to KFTS, CBC, cardiac, liver enzymes and lipid profile as shown in Table 5. There was no difference in KFTS \& CBC. But, there was a difference in cardiac enzymes (troponin I) which was more in Group 1 (S. Bil < 1) with significant $\mathrm{p}$ value $(0.02)$, also (ALT, AST) were more in Group 1 ( $\mathrm{p}$ value $=0.01$ ).

All study population had detailed transthoracic echocardiogram. The Following parameters had obtained (LVEDD, LVESD, EF BY M mode, E/A ratio, PASP). 
Table 1. Serum bilirubin in studied cases.

\begin{tabular}{ccc}
\hline S. Bil Groups & Group 1 & Group 2 \\
\hline Number (70) & 49 & 21 \\
Ratio \% (100\%) & $70 \%$ & $30 \%$ \\
\hline
\end{tabular}

Table 2. Risk factors in studied groups.

\begin{tabular}{cccc}
\hline Risk Factors & Group 1 $(\mathrm{N}=49)$ & Group 2 $(\mathrm{N}=21)$ & p value \\
HTN $(\mathrm{N}=41)$ & 30 & 11 & 0.232 \\
DM $(\mathrm{N}=45)$ & 33 & 15 & 0.736 \\
Smokers $(\mathrm{N}=37)$ & 29 & 8 & 0.105 \\
\hline
\end{tabular}

Table 3. E.C.G presentation in studied cases.

\begin{tabular}{cccccccc}
\hline E.C.G & Ant STE & $\begin{array}{c}\text { Ext Ant } \\
\text { STE }\end{array}$ & $\begin{array}{c}\text { Inf Post } \\
\text { STE }\end{array}$ & Inf STE & RV inf Lat STE Post STE \\
\hline Number (70) & 27 & 6 & 5 & 24 & 4 & 3 & 1 \\
Ratio \% (100\%) & $39 \%$ & $9 \%$ & $7 \%$ & $34 \%$ & $6 \%$ & $4 \%$ & $1 \%$ \\
\hline
\end{tabular}

Table 4. Affected coronary vessels in studied groups.

\begin{tabular}{cccc}
\hline Affected Coronary vs Group & Group $1(\mathrm{~N}=49)$ & Group 2 $(\mathrm{N}=21)$ & p value \\
\hline One Vs $(\mathrm{n}=39)$ & $24(48 \%)$ & $15(71 \%)$ & 0.003 \\
$>$ one Vs $(\mathrm{n}=31)$ & $25(52 \%)$ & $6(29 \%)$ & \\
\hline
\end{tabular}

Table 5. Comparison between studied groups regarding laboratory finding.

\begin{tabular}{cccc}
\hline & & S. Bilirubin & \\
Laboratory data & Group 1 & Group 2 & p value \\
\cline { 2 - 4 } & Mean \pm SD & $0.99 \pm 0.36$ & 0.156 \\
Creatinine & $1.13 \pm 0.38$ & $13.17 \pm 1.73$ & 0.624 \\
Hb & $13.38 \pm 1.6$ & $14.86 \pm 3.88$ & 0.156 \\
TLC & $16.12 \pm 3.14$ & $340 \pm 62.29$ & 0.406 \\
PLT & $351.03 \pm 44.82$ & $3.22 \pm 2.74$ & $0.02^{\star}$ \\
Troponin & $6.41 \pm 5.93$ & $61.19 \pm 9.29$ & $0.01^{*}$ \\
ALT & $73.53 \pm 20.46$ & $44.1 \pm 5.06$ & $0.01^{\star}$ \\
AST & $48.71 \pm 7.6$ & $120.05 \pm 21.33$ & 0.73 \\
LDL & $118.24 \pm 19.5$ & $40.67 \pm 7.36$ & 0.362 \\
HDL & $38.85 \pm 7.72$ & $224.76 \pm 30.76$ & 0.919 \\
TC & $223.79 \pm 38.55$ & $190.48 \pm 47.69$ & 0.079 \\
TG & $213.09 \pm 49.08$ & & \\
\hline & & & \\
\hline
\end{tabular}

By comparing the two groups, there was a significant difference regarding (EF) between both which was less in Group $1(\mathrm{~S} . \mathrm{TB}<1)$ than Group $2(\mathrm{~S} . \mathrm{TB}>1)$ 
mean EF (47.94 vs 58.33 regarding Groups $1 \& 2$ in order), p value significance (0.0001). Also by comparing LVESD between both groups, it was more increased in Group 1 than Group 2, mean LVESD (37.62 vs. 34.29), p value significance (0.0006). For other parameters (LVEDD, PASP \& E/A) there was no significant difference between both groups (Table 6).

GENSENI score was calculated to all study population. Classified to three groups mild form of CAD (0 - 23), Moderate CAD (24 - 53) \& severe CAD (>54). Most studied population had a severe form of CAD (59\%). As shown in Table 7.

As shown in Figure 1, there was a significant difference between both groups as GENSENI was more in Group $1(\mathrm{~S} . \mathrm{TB}<1)$ than Group $2(\mathrm{~S} . \mathrm{TB}>1)$ with mean (80.35 vs 34.71$)$. Significant p value $(0.0001)$.

As shown in Table 8 there was highly significant negative correlation between serum bilirubin \& GENSENI score $(r=-0.762$, $p$ value 0.0001$)$.

Complications during \& post PCI were studied in both groups as shown in Table 9. Among 70 patients, 54 patients (67\%) had developed a complication in the form of ventricular arrhythmias, cardiogenic shock, aborted cardiac arrest, death \& heart failure. By comparing the two studied groups regarding (incidence of complications), incidence was more in Group $1(\mathrm{~S} . \mathrm{TB}<1)$ than in Group 2 $(\mathrm{S} . \mathrm{TB}>1)$, which means a significant difference between both groups with significant $\mathrm{p}$ value (0.0001). Arrhythmia was the most frequent complication (37\%) followed by heart failure (16\%) then cardiogenic shock (14\%). The least were aborted cardiac arrest (7\%) \& death (2\%).

As shown in Table 10, there was a significant negative correlation between serum bilirubin \& incidence of complications $(R=-0.38$, $p$ value 0.001$)$.

As shown in Table 11, there was a significant negative correlation between GENSINI score, complication and bilirubin among both groups ( $\mathrm{r}$ : $-0.762 \backslash-0.38)$ with $\mathrm{p}$ value $(0.0001 \backslash 0.001)$ respectively.

Table 6. Showing echo findings in two studied groups.

\begin{tabular}{cccc}
\hline & \multicolumn{3}{c}{ S. Bilirubin } \\
\cline { 2 - 4 } Echo data & $\begin{array}{c}\text { Group 1 } \\
\text { Mean } \pm \text { SD }\end{array}$ & $\begin{array}{c}\text { Group 2 } \\
\text { Mean } \pm \text { SD }\end{array}$ & p value \\
\hline LVEDD & $51.85 \pm 3.02$ & $51.62 \pm 2.91$ & 0.768 \\
LVESD & $37.62 \pm 3.86$ & $34.29 \pm 2.72$ & $0.0006^{*}$ \\
EF \% & $47.94 \pm 9.2$ & $58.33 \pm 5.52$ & $0.0001^{*}$ \\
PASP & $41.65 \pm 8.72$ & $39.52 \pm 6.31$ & 0.316 \\
E/A & $0.88 \pm 0.3$ & $0.86 \pm 0.24$ & 0.787 \\
\hline
\end{tabular}

Table 7. GENSENI score in studied cases.

\begin{tabular}{cccc}
\hline GENSENI Group & $\mathbf{0 - 2 3}$ & $\mathbf{2 4}-\mathbf{5 3}$ & $\mathbf{5 4}$ \\
\hline Number (70) & 2 & 27 & 41 \\
Ratio \% (100\%) & $2 \%$ & $39 \%$ & $59 \%$ \\
\hline
\end{tabular}


Table 8. Correlation between S. Bilirubin \& GENSENI score in studied cases.

\begin{tabular}{ccc}
\hline & \multicolumn{3}{c}{ GENSENI Score } \\
\cline { 2 - 3 } & $\mathbf{R}$ & p value \\
\hline S. Bilirubin & -0.762 & $0.0001^{*}$ \\
\hline
\end{tabular}

*significant correlation, r: correlation coefficient.

Table 9. Complications in studied groups.

\begin{tabular}{cccccc}
\hline Complication & Arrhythmia & Shock & Death & Cardiac Arrest & Heart Failure \\
\hline Number (70) & 26 & 10 & 2 & 5 & 11 \\
Ratio \% (100\%) & $37 \%$ & $14 \%$ & $2 \%$ & $7 \%$ & $16 \%$ \\
Group 1 & 20 & 7 & 2 & 5 & 10 \\
Group 2 & 6 & 3 & 0 & 0 & 1 \\
p value & & & $0.0001^{*}$ & \\
\hline
\end{tabular}

Table 10. Correlation between serum bilirubin \& incidence of complications in studied cases.

\begin{tabular}{ccc}
\hline & \multicolumn{3}{c}{ Complications } \\
\cline { 2 - 3 } & $\mathbf{R}$ & p value \\
\hline S. Bilirubin & -0.38 & $0.001^{*}$ \\
\hline
\end{tabular}

Table 11. Correlation between S. Bilirubin, GENSENI score \& complications in studied groups.

\begin{tabular}{ccc}
\hline & \multicolumn{2}{c}{ S. Bilirubin } \\
\cline { 2 - 3 } & $\mathbf{R}$ & p value \\
\hline GENSENI Score & -0.762 & $0.0001^{*}$ \\
Complication & -0.38 & $0.001^{\star}$ \\
\hline
\end{tabular}

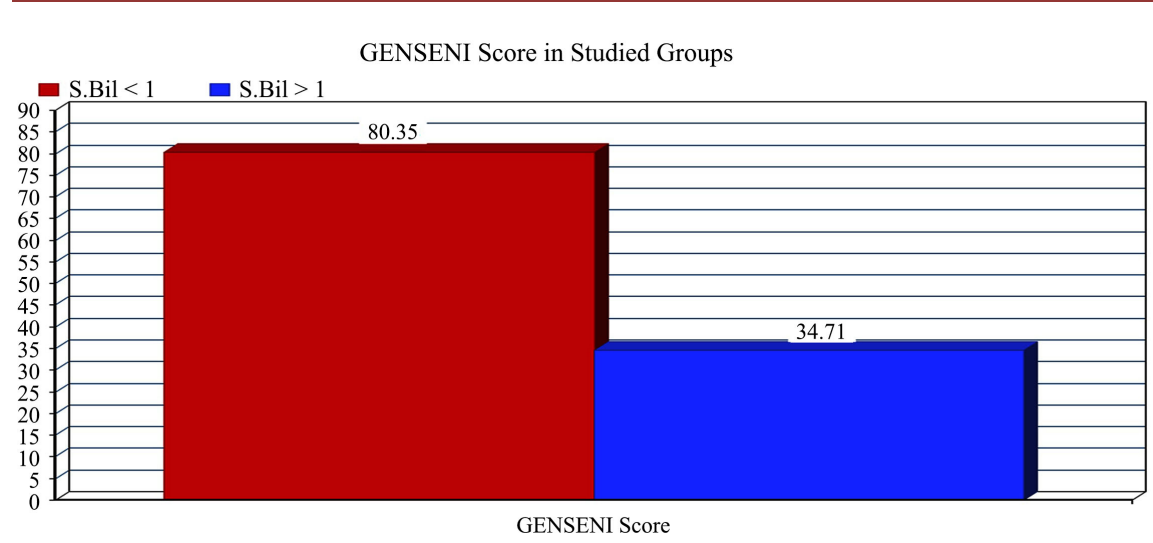

Figure 1. Comparison between the two groups regarding GENSENI score.

\section{Discussion}

Cardiovascular disease, mainly acute myocardial infarction is the most common 
cause of mortality in developed countries and accounts for up to one-third of all deaths worldwide [18]. The remarkable prevalence of cardiovascular diseases in today's society high lights the necessity of the identification of risk factors and screening of vulnerable individuals in using preventive and treatment methods.

Although the pathogenesis of atherosclerosis has not been thoroughly investigated, oxidative stress and DNA damage induced by oxidized low-density lipoprotein (LDL) cholesterol and by diet-induced hypercholesterolemia contribute to the progression of atherosclerosis [19]. Therefore, antioxidants are thought to serve a protective role against atherosclerosis and coronary artery disease by preventing the oxidative modification of LDL cholesterol [20].

Bilirubin is a potent antioxidant under physiological conditions and suppresses the oxidation of lipids and lipoproteins. Thus, bilirubin has been demonstrated in vitro to prevent plaque formation and subsequent formation of atherosclerosis [21]. Several mechanisms have been attributed to anti-atherogenic property of bilirubin. The first protective effect of bilirubin relates to the antioxidant property of bilirubin, which prevents lipid oxidation, especially Lowdensity lipoprotein (LDL), and inhibits free radical-induced damages.

In 2013, Stojanov et al. reported cardio protective effects of increased levels of bilirubin in 628 healthy subjects. The subjects were 442 men and 186 women aged 18 to 52 years. They divided the subjects into two groups based on levels of bilirubin. Subjects with level below the upper limit of reference were classified as "low bilirubin" ( $\leq 0.95 \mathrm{mg} / \mathrm{dL}$ in women and $\leq 1.4 \mathrm{mg} / \mathrm{dL}$ in men) and those with a value above the upper limit of reference were classified as "high bilirubin". Men with high bilirubin concentration $(>1.4 \mathrm{mg} / \mathrm{dL})$ had higher concentration of albumin and uric acid ( $\mathrm{p}<0.001)$ and lower level of oxidized LDL $(\mathrm{p}<0.05)$. In females, high bilirubin $(>0.95 \mathrm{mg} / \mathrm{dL})$ was associated with significantly higher albumin $(\mathrm{p}<0.05)$ and lower thiobarbituric acid-reacting substances (TBARS) $(p<0.05)$. These findings support the evidence of an anti-oxidant effect of bilirubin secondary to inverse association with ox-LDL and anti-inflammatory effect secondary to direct correlation with albumin, which is a negative acute phase reactant in inflammatory response [22].

It was observed that serum bilirubin was significantly negatively associated with incident hyper LDL cholesterolemia in a health screening population [23]. The profound hypocholesterolemia and hypotriglyceridemia found in a murine model of hyperbilirubinemia (Gunn rat) suggest that an increase in serum bilirubin levels may decrease serum levels of cholesterol and triglycerides [24].

The second protective effect relates to the anti-complement and anti-inflammation properties of bilirubin. This effect is introduced through different forms of bilirubin including direct bilirubin [25].

In regard to our study, there was significant inverse relationship between serum total bilirubin and severity of CAD by angiographic assessment with Genseni score as patients in Group 1 (serum T.B $<1$ ) had higher Genseni score in comparison to Group 2 (serum T.B > 1), with mean (80.35 vs. 34.71). Significant 
$\mathrm{p}$ value $(0.0001)$

The same result was observed by Akboga et al. (2015) who conducted a study evaluating anti-inflammatory properties of bilirubin. In a retrospective crosssectional study, they included 1501 patients who underwent coronary angiography. They divided them into three groups based on Gensini scores: No CAD (control group, $\mathrm{n}=380)$, mild CAD $(\mathrm{n}=497)$ and severe CAD $(\mathrm{n}=624)$, with the objective of establishing anti-inflammatory effects of bilirubin in addition to its anti-oxidant effects. A significant inverse correlation between total bilirubin and C-reactive protein $(r=-0.112, p<0.001)$, neutrophil to lymphocyte ratio ( $r$ $=-0.070, \mathrm{p}=0.026)$ and red cell distribution width $(\mathrm{r}=-0.074, \mathrm{p}=0.027)$ was observed. These findings helped establish anti-inflammatory properties of bilirubin in addition to their anti-oxidant effects. They also reconfirmed the inverse association of bilirubin with CAD severity (spearman's rank correlation coefficient $(\mathrm{r})=-0.173, \mathrm{p}<0.001)[26]$.

In another study, 221 patients who were evaluated for CAD by coronary angiography showed a moderate but significant positive correlation between direct bilirubin levels and the Gensini score $(r=0.158, p=0.019)$. However, no such significant correlation was demonstrated between total bilirubin and the Gensini score. This study was limited by its small sample size $(n=221)$ [27].

Also in our study, we found that there was inverse relationship between serum bilirubin and the number of affected vessels as patients in Group 1 had more affected vessels than Group 2 ( $52 \%$ vs. $29 \%$, p value 0.003 ).

The same result was obtained by Taban Sadeghi et al. (2015) who evaluated the relation between serum bilirubin levels with coronary diseases based on angiographic findings, a significant difference was observed between verge total bilirubin levels in two groups: patients with normal angiography \& with 3 vessels involved, A reverse relation was observed in this study between total bilirubin levels, number of vessels affected, the severity of stenosis and type of coronary vessel [28].

Wei et al. (2012) also showed similar results with a significant inverse correlation between CAD and total bilirubin $(\mathrm{n}=1260)$ in patients who underwent coronary angiography [12].

Shortly after that study, Canpolat et al. (2013) used computed tomographic angiography (CTA) to evaluate the relationship between bilirubin levels and nature of coronary plaques. The study included 1115 subjects who underwent CTA for evaluation of CAD. Patients were divided into 4 quartiles depending on the total bilirubin level. Patients with any coronary plaque were observed to have statistically significant lower levels of serum bilirubin $(p=0.002)$. Patients with critical stenosis ( $>50 \%$ obstruction) had lower bilirubin levels compared to non-critical stenosis $(0.57 \pm 0.18 \mathrm{mg} / \mathrm{dL}$ vs $0.70 \pm 0.24 \mathrm{mg} / \mathrm{dL}, \mathrm{p}<0.001)$. The authors concluded that lower serum levels of bilirubin were significantly associated with the presence, severity and the non-calcified morphology of atherosclerotic plaques [29]. 
In our study, there was no significant relation between serum bilirubin and studied risk factors like (HTN, DM \& smoking).

Unlikely Taban et al. (2015) who reported that total bilirubin concentration was slightly higher in smokers $(1.24 \pm 0.08)$ compared with non-smokers (1.24 \pm $0.03)$, but the difference was not significant $(\mathrm{p}=0.31)$ [28]. Endler et al. (2003) however, reported that total bilirubin concentration was significantly lower in smokers as compared to non-smokers, in contrast to our study [30].

In the present study, there was a significant difference regarding $(E F)$ between both groups which was less in Group $1(\mathrm{~S} . \mathrm{TB}<1)$ than Group $2(\mathrm{~S} . \mathrm{TB}>1)$ mean EF (47.94 vs 58.33 regarding Groups $1 \& 2$ in order), with significant $p$ value (0.0001). Also by comparing LVESD between both groups, it was more increased in Group 1 than Group 2, mean LVESD (37.62 vs 34.29), with significant p value (0.0006).

Complications during \& post PCI were studied in both groups. Among 70 patients, 54 patients (67\%) had developed a complication in the form of ventricular arrhythmias, cardiogenic shock, aborted cardiac arrest, death \& heart failure. By comparing the two studied groups regarding (incidence of complications), incidence was more in Group $1(\mathrm{~S} . \mathrm{TB}<1)$ than in Group 2 ( $\mathrm{S} . \mathrm{TB}>1)$, which means a significant difference between both groups with significant $\mathrm{p}$ value $(0.0001)$. Arrhythmia was the most frequent complication (37\%) followed by heart failure (16\%) then cardiogenic shock (14\%). The least were aborted cardiac arrest (7\%) \& death $(2 \%)$.

These results are in agreement with the results of Gul et al. (2013) who found that high serum TB $>0.9 \mathrm{mg} / \mathrm{dl}$ is a predictor of in-hospital cardiovascular mortality and complications in patients with STEMI, and the results of Chung et al. (2016) who found a higher incidence of MACEs in patients of STEMI with high serum $\mathrm{TB}>0.79 \mathrm{mg} / \mathrm{dl}$ after primary PCI [31].

Also, these results were in agreement with the results of Acet et al. (2014) who found that higher serum TB is a predictor of impaired pretreatment infarct related artery (IRA) patency and poor outcome after primary PCI [32]. Add to this, Baumann et al. (2016) who showed that high serum TB have prognostic association with in-hospital major adverse cardiac events (MACEs) in male patients with myocardial infarction [33].

This association between increased total bilirubin and adverse outcome after STEMI can be explained by the effect of acute stress on the expression of heme oxygenase-1 (HO-1) enzyme with a resultant increase in its level and the level of its product bilirubin in the blood [31] [32] [33] [34].

No significant relation was observed in reviewing the relation of MACE with serum total bilirubin level, but no major cardiac events were seen in the patients with high bilirubin levels, but were observed in the patients with low bilirubin level. Total bilirubin was not known as a predictor for MACE as well. In this regard, in Sahin et al., study in 2013, no significant relation was observed between the numbers of cardiac events in two groups with high and low bilirubin levels 
[35], which is congruent with the results of study of Gul et al. (2013) revealed that number of hospital events was significantly higher in the group with high total bilirubin compared to the group with low total bilirubin [31].

This prospective study demonstrates that the serum bilirubin SB concentration was associated with the MACE in CAD patients after PCI. The higher the concentration of serum total bilirubin, the lower the incidence of MACE including MI, ischemia, driven target-vessel revascularization, heart failure, and cardiac death after PCI.

\section{Conclusion}

An overall conclusion of the present study is that high serum total bilirubin (TB) in patients with STEMI is associated with low incidence of complications especially arrhythmia, heart failure, cardiogenic shock, increased ejection fraction (EF) and decreased number of vessels which are affected. According to GENSINI score, severity was higher as serum bilirubin decreased. TB can be used as an inexpensive and immediately obtainable blood test for the prediction of outcome in STEMI patient subjected to PCI.

\section{Acknowledgements}

We acknowledge the directors and personnel of the El-Mahalla cardiology center, El Mahalla elkubra, Egypt.

\section{Conflicts of Interest}

The authors declare no conflicts of interest regarding the publication of this paper.

\section{References}

[1] Lozano, R., Naghavi, M., Foreman, K., Lim, S., Shibuya, K., Aboyans, V., Abraham, J., Adair, T., Aggarwal, R., Ahn, S.Y. and AlMazroa, M.A. (2012) Global and Regional Mortality from 235 Causes of Death for 20 Age Groups in 1990 and 2010: A Systematic Analysis for the Global Burden of Disease Study 2010. The Lancet, 380, 2095-2128. https://doi.org/10.1016/S0140-6736(12)61728-0

[2] Chatzizisis, Y.S., Coskun, A.U., Jonas, M., Edelman, E.R., Feldman, C.L. and Stone, P.H. (2007) Role of Endothelial Shear Stress in the Natural History of Coronary Atherosclerosis and Vascular Remodeling: Molecular, Cellular, and Vascular Behavior. Journal of the American College of Cardiology, 49, 2379-2393. https://doi.org/10.1016/j.jacc.2007.02.059

[3] Thygesen, K., Alpert, J.S., Jaffe, A.S., Simoons, M.L., Chaitman, B.R. and White, H.D. (2012) Third Universal Definition of Myocardial Infarction. Circulation, 126, 2020-2035. https://doi.org/10.1161/CIR.0b013e31826e1058

[4] Boersma, E. (2006) Does Time Matter? A Pooled Analysis of Randomized Clinical Trials Comparing Primary Percutaneous Coronary Intervention and In-Hospital Fibrinolysis in Acute Myocardial Infarction Patients. European Heart Journal, 27, 779-788. https://doi.org/10.1093/eurheartj/ehi810

[5] Pae, H.O., Son, Y., Kim, N.H., Jeong, H.J., Chang, K.C. and Chung, H.T. (2010) 
Role of Heme Oxygenase in Preserving Vascular Bioactive NO. Nitric Oxide, 23, 251-257. https://doi.org/10.1016/j.niox.2010.08.002

[6] Kundur, A.R., Singh, I. and Bulmer, A.C. (2015) Bilirubin, Platelet Activation and Heart Disease: A Missing Link to Cardiovascular Protection in Gilbert's Syndrome? Atherosclerosis, 239, 73-84. https://doi.org/10.1016/j.atherosclerosis.2014.12.042

[7] Wagner, K.H., Wallner, M., Mölzer, C., Gazzin, S., Bulmer, A.C., Tiribelli, C. and Vitek, L. (2015) Looking to the Horizon: The Role of Bilirubin in the Development and Prevention of Age-Related Chronic Diseases. Clinical Science, 129, 1-25. https://doi.org/10.1042/CS20140566

[8] Rigato, I., Ostrow, J.D. and Tiribelli, C. (2005) Bilirubin and the Risk of Common Non-Hepatic Diseases. Trends in Molecular Medicine, 11, 277-283. https://doi.org/10.1016/j.molmed.2005.04.008

[9] Hansson, G.K., Robertson, A.K. and Söderberg-Nauclér, C. (2006) Inflammation and Atherosclerosis. Annual Review of Pathology: Mechanisms of Disease, 1, 297-329. https://doi.org/10.1146/annurev.pathol.1.110304.100100

[10] Louise, D. (2012) Bilirubin Protects against Heart Disease. Medical Xpress.

[11] Erdogan, T., Çiçek, Y., Kocaman, S.A., Çanga, A., Çetin, M., Durakoglugil, E., Şatiroglu, Ö., Temiz, A., Ergül, E., Şahin, I. and Bostan, M. (2012) Increased Serum Bilirubin Level Is Related to Good Collateral Development in Patients with Chronic Total Coronary Occlusion. Internal Medicine, 51, 249-255.

[12] Wei, S., Gao, C., Wei, G., Chen, Y., Zhong, L. and Li, X. (2012) The Level of Serum Bilirubin Associated with Coronary Lesion Types in Patients with Coronary Artery Disease. Journal of Cardiovascular Medicine, 13, 432-438. https://doi.org/10.2459/JCM.0b013e32834a3967

[13] Salari, A., Moaddab, F., Pourabdollah Tootkaboni, M., Shakiba, M. and Poursadeghi, M. (2017) The Relation of Serum Bilirubin Level with the Severity and Complexity of Coronary Artery Disease and Long-term Outcomes in the Patients Undergoing Primary Percutaneous Coronary Intervention. International Journal of Medical Laboratory, 4, 48-55.

[14] Braunwald, E., Zipes, D.P., Libby, P. and Bonow, R. (2004) Braunwald's Heart Disease: A Text Book of Cardiovascular Medicine. Vol. 2, 7th Edition, Saunders, Philadelphia.

[15] Smith Jr., S.C., Dove, J.T., Jacobs, A.K., Kennedy, J.W., Kereiakes, D., Kern, M.J., Kuntz, R.E., Popma, J.J., Schaff, H.V., Williams, D.O. and Gibbons, R.J. (2001) ACC/AHA Guidelines for Percutaneous Coronary Intervention (Revision of the 1993 PTCA Guidelines)_Executive Summary: A Report of the American College of Cardiology/American Heart Association Task Force on Practice Guidelines (Committee to Revise the 1993 Guidelines for Percutaneous Transluminal Coronary Angioplasty) Endorsed by the Society for Cardiac Angiography and Interventions. Circulation, 103, 3019-3041. https://doi.org/10.1161/01.CIR.103.24.3019

[16] Hayashi, M., Fujimoto, K., Urushibata, K., Uchikawa, S.I., Imamura, H. and Kubo, K. (2003) Nocturnal Oxygen Desaturation Correlates with the Severity of Coronary Atherosclerosis in Coronary Artery Disease. Chest, 124, 936-941. https://doi.org/10.1378/chest.124.3.936

[17] Nurkalem, Z., Hasdemir, H., Ergelen, M., Aksu, H., Sahin, I., Erer, B., Yilmaz, H.Y., Comert, N., Sargin, M. and Eren, M. (2010) The Relationship between Glucose Tolerance and Severity of Coronary Artery Disease Using the Gensini Score. Angiology, 61, 751-755. https://doi.org/10.1177/0003319710373747

[18] Kang, S.J., Kim, D., Park, H.E., Chung, G.E., Choi, S.H., Choi, S.Y., Lee, W., Kim, 
J.S. and Cho, S.H. (2013) Elevated Serum Bilirubin Levels Are Inversely Associated with Coronary Artery Atherosclerosis. Atherosclerosis, 230, 242-248. https://doi.org/10.1016/j.atherosclerosis.2013.06.021

[19] Ceaser, E.K., Ramachandran, A., Levonen, A.L. and Darley-Usmar, V.M. (2003) Oxidized Low Density Lipoprotein and 15-Deoxy- $\Delta^{12,14}-\mathrm{PGJ}_{2}$ Increase Mitochondrial Complex I Activity in Endothelial Cells. American Journal of Physiology-Heart and Circulatory Physiology, 285, H2298-H2308. https://doi.org/10.1152/ajpheart.00508.2003

[20] Frankel, E.N., German, J.B., Kinsella, J.E., Parks, E. and Kanner, J. (1993) Inhibition of Oxidation of Human Low-Density Lipoprotein by Phenolic Substances in Red Wine. The Lancet, 341, 454-457. https://doi.org/10.1016/0140-6736(93)90206-V

[21] Stocker, R., Yamamoto, Y., McDonagh, A.F., Glazer, A.N. and Ames, B.N. (1987) Bilirubin Is an Antioxidant of Possible Physiological Importance. Science, 235, 1043-1046. https://doi.org/10.1126/science.3029864

[22] Stojanov, M., Stefanovic, A., Dzingalasevic, G., Ivanisevic, J., Miljkovic, M., Mandic-Radic, S. and Prostran, M. (2013) Total Bilirubin in Young Men and Women: Association with Risk Markers for Cardiovascular Diseases. Clinical Biochemistry, 46, 1516-1519. https://doi.org/10.1016/j.clinbiochem.2013.06.020

[23] Oda, E. (2014) A Decrease in Total Bilirubin Predicted Hyper-LDL Cholesterolemia in a Health Screening Population. Atherosclerosis, 235, 334-338. https://doi.org/10.1016/j.atherosclerosis.2014.05.927

[24] Boon, A.C., Hawkins, C.L., Bisht, K., Coombes, J.S., Bakrania, B., Wagner, K.H. and Bulmer, A.C. (2012) Reduced Circulating Oxidized LDL Is Associated with Hypocholesterolemia and Enhanced Thiol Status in Gilbert Syndrome. Free Radical Biology and Medicine, 52, 2120-2127. https://doi.org/10.1016/j.freeradbiomed.2012.03.002

[25] Kang, S.J., Lee, C. and Kruzliak, P. (2014) Effects of Serum Bilirubin on Atherosclerotic Processes. Annals of Medicine, 46, 138-147. https://doi.org/10.3109/07853890.2014.895588

[26] Akboga, M.K., Canpolat, U., Sahinarslan, A., Alsancak, Y., Nurkoc, S., Aras, D., Aydogdu, S. and Abaci, A. (2015) Association of Serum Total Bilirubin Level with Severity of Coronary Atherosclerosis Is Linked to Systemic Inflammation. Atherosclerosis, 240, 110-114. https://doi.org/10.1016/j.atherosclerosis.2015.02.051

[27] V'itek, L., Jirsa Jr., M., Brodanová, M., Kaláb, M., Mareček, Z., Danzig, V., Novotný, L. and Kotal, P. (2002) Gilbert Syndrome and Ischemic Heart Disease: A Protective Effect of Elevated Bilirubin Levels. Atherosclerosis, 160, 449-456. https://doi.org/10.1016/S0021-9150(01)00601-3

[28] Taban, S.M., Golmohammadi, A., Parvizi, R., Kezerlou, A.N., Separham, A. and Hosnavi, Z. (2015) The Relation of Serum Bilirubin Level with Coronary Artery Disease Based on Angiographic Findings. Crescent Journal of Medical and Biological Sciences, 2, 130-134.

[29] Canpolat, U., Aytemir, K., Yorgun, H., Hazırolan, T., Kaya, E.B., Şahiner, L., Sunman, H., Tokgözoğlu, L., Kabakc1, G. and Oto, A. (2013) Association of Serum Total Bilirubin Levels with the Severity, Extent and Subtypes of Coronary Atherosclerotic Plaques Detected by Coronary CT Angiography. The International Journal of Cardiovascular Imaging, 29, 1371-1379. https://doi.org/10.1007/s10554-013-0209-7

[30] Endler, G., Hamwi, A., Sunder-Plassmann, R., Exner, M., Vukovich, T., Mannhalter, C., Wojta, J., Huber, K. and Wagner, O. (2003) Is Low Serum Bilirubin an Independent Risk Factor for Coronary Artery Disease in Men but Not in Women? 
Clinical Chemistry, 49, 1201-1204. https://doi.org/10.1373/49.7.1201

[31] Gul, M., Uyarel, H., Ergelen, M., Akgul, O., Karaca, G., Turen, S., Ugur, M., Ertürk, M., Kul, S., Surgit, O. and Bozbay, M. (2013) Prognostic Value of Total Bilirubin in Patients with ST-Segment Elevation Acute Myocardial Infarction Undergoing Primary Coronary Intervention. The American Journal of Cardiology, 111, 166-171. https://doi.org/10.1016/j.amjcard.2012.09.011

[32] Acet, H., Ertş, F., Akıl, M.A., Polat, N., Aydın, M., Akyüz, A., Ayçiçek, H. and Alan, S. (2014) A Novel Predictor of Infarct-Related Artery Patency before Percutaneous Intervention and In-Hospital Outcomes for ST-Segment Elevation Myocardial Infarction Patients: Serum Bilirubin Level. Postepy $w$ Kardiologii Interwencyjnej $=$ Advances in Interventional Cardiology, 10, 91-97.

https://doi.org/10.5114/pwki.2014.43513

[33] Baumann, S., Huseynov, A., Koepp, J., Jabbour, C., Behnes, M., Becher, T., Renker, M., Lang, S., Borggrefe, M., Lehmann, R. and Akin, I. (2016) Comparison of Serum Uric Acid, Bilirubin, and C-Reactive Protein as Prognostic Biomarkers of In-Hospital MACE between Women and Men with ST-Segment Elevation myocArdial Infarction. Angiology, 67, 272-280. https://doi.org/10.1177/0003319715589246

[34] Hayashi, S., Omata, Y., Sakamoto, H., Higashimoto, Y., Hara, T., Sagara, Y. and Noguchi, M. (2004) Characterization of Rat Heme Oxygenase-3 Gene. Implication of Processed Pseudogenes Derived from Heme Oxygenase-2 Gene. Gene, 336, 241-250. https://doi.org/10.1016/j.gene.2004.04.002

[35] Şahin, Ö., Akpek, M., Karadavut, S., Coşgun, M.S., Savaş, G., Şarlı, B. and Kaya, M.G. (2013) Relation between Serum Total Bilirubin Levels and Severity of Coronary Artery Disease in Patients with Non ST Elevation Myocardial Infarction. Journal of the American College of Cardiology, 62, C217-C218. https://doi.org/10.1016/j.jacc.2013.08.613 